\title{
Extracorporeal membrane oxygenation for septic shock: Heroic futility?
}

\author{
Francis D. Pagani, MD, PhD
}

From the Department of Cardiac Surgery, University of Michigan, Ann Arbor, Mich.

Disclosures: Author has nothing to disclose with regard to commercial support.

Received for publication April 15, 2018; accepted for publication April 16, 2018; available ahead of print June 5, 2018

Address for reprints: Francis D. Pagani, MD, PhD, Department of Cardiac Surgery, 5161 Cardiovascular Center,

University of Michigan, 1500 East Medical Center Dr, Ann Arbor, MI 48109 (E-mail: fpagani@umich.edu).

J Thorac Cardiovasc Surg 2018;156:1110-1

$0022-5223 / \$ 36.00$

Copyright $(5) 2018$ by The American Association for Thoracic Surgery

https://doi.org/10.1016/j.jtcvs.2018.04.076

Septic shock is a prevalent complication of infection in critically ill patients that can be associated with profound myocardial depression. ${ }^{1}$ Despite advances in supportive critical care and the availability of targeted antimicrobial therapy, mortality remains high as a consequence of compromised organ perfusion and multisystem organ failure. For septic shock unresponsive to all conventional treatments, venoarterial extracorporeal membrane oxygenation (VA-ECMO) has been increasingly applied as a salvage therapy. ${ }^{2,3}$ In neonates and children, the use of extracorporeal membrane oxygenation (ECMO) has been associated with improved survival and is considered a viable option for this population. ${ }^{4}$ For adults, the use of ECMO has not provided similar benefit and results from multiple single-center series have been variable and its use in adults remains debatable. ${ }^{5}$ In part, differences in patient outcomes in adults have been related to patient selection as some series have included patients requiring venovenous ECMO for sepsis-associated respiratory failure, whereas other series have included only adult patients with hemodynamic compromise requiring VA-ECMO. ${ }^{6}$

In this issue of The Journal of Thoracic and Cardiovascular Surgery, Ro et al $^{7}$ report on a single-center experience of 71 patients who received VA-ECMO support for septic shock. The investigators compared results of VA-ECMO support for septic shock with 253 patients who received VA-ECMO for cardiogenic shock. Ro et al observed that of the total of 71 patients who received VA-ECMO for septic shock, only $15.5 \%$ were successfully weaned from ECMO with only $7.0 \%$ surviving to hospital discharge. The investigators also observed lower Sepsis-related Organ Failure Assessment scores in survivors and higher arterial lactate levels, lower platelet count, and higher total bilirubin levels in nonsurvivors. However, these trends were not statistically significant. In comparison, of the 253 patients who received VA-ECMO for cardiogenic shock, $45.5 \%$ were successfully weaned and $28.9 \%$ were discharged from the hospital.

The observations by Ro et al are relevant and represent one of the larger series of patients who received

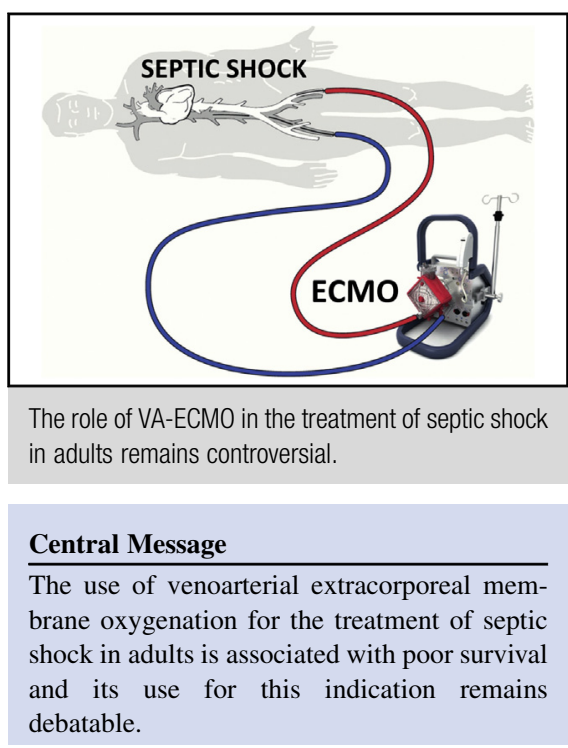

See Article page 1104.

VA-ECMO for cardiogenic shock and justifiably give pause to the use of ECMO for this indication. However, the study has a number of limitations and include the inherent limitations of a single-center, retrospective, observational study of a small patient cohort. Often, significant bias is introduced into such studies because of patient selection. In the study by Ro et $\mathrm{al}^{7}$ the inclusion of a patient cohort with a high prevalence of liver disease could adversely affect outcomes. Further, the study cohort was derived from the years 2005 through 2012. Whether improved outcomes would have been obtained from a more contemporary cohort is unknown.

Should ECMO be abandoned for treatment of refractory shock in adults as suggested by the authors? It is too early to place the "nail in the coffin" for VA-ECMO for this indication. What is needed is a better understanding of the factors leading to poor outcomes that could lead to improvements in patient selection and development of adjuvant therapies. ${ }^{8,9}$ Larger registry-based studies could also facilitate recruitment of a larger patient cohort to investigate, at a more granular level, what factors contribute to poor outcomes and set the stage for prospective interventions.

\section{References}

1. Ellrodt AG, Riedinger MS, Kimchi A, Berman DS, Maddahi J, Swan HJ, et al. Left ventricular performance in septic shock: Reversible segmental and global abnormalities. Am Heart J. 1985;110:402-9. 
2. Park TK, Yang JH, Jeon K, Choi SH, Choi JH, Gwon HC, et al. Extracorporeal membrane oxygenation for refractory septic shock in adults. Eur J Cardiothorac Surg. 2015;47:e68-74.

3. Huang CT, Tsai YJ, Tsai PR, Ko WJ. Extracorporeal membrane oxygenation resuscitation in adult patients with refractory septic shock. J Thorac Cardiovasc Surg. 2013;146:1041-6.

4. Brierley J, Carcillo JA, Choong K, Cornell T, Decaen A, Deymann A, et al. Clinical practice parameters for hemodynamic support of pediatric and neonatal septic shock: 2007 update from the American College of Critical Care Medicine. Crit Care Med. 2009;37:666-88.

5. Combes A. Role of VA ECMO in septic shock: does it work? Available at: https:// doi.org/10.5339/qmj.2017.swacelso.24. Accessed April 25, 2018.
6. Choi MJ, Ha SO, Kim HS, Park S, Han SJ, Lee SH. The Simplified Acute Physiology Score II as a predictor of mortality in patients who underwent extracorporeal membrane oxygenation for septic shock. Ann Thorac Surg. 2017; 103: 1246-53.

7. Ro SK, Kim WK, Lim JY, Yoo JS, Hong SB, Kim JB. Extracorporeal life support for adults with refractory septic shock. J Thorac Cardiovasc Surg. 2018;156: 1104-9.e1.

8. Ronco C, Piccinni P, Kellum J. Rationale of extracorporeal removal of endotoxin in sepsis: theory, timing and technique. Contrib Nephrol. 2010;167: 25-34.

9. House AA, Ronco C. Extracorporeal blood purification in sepsis and sepsis-related acute kidney injury. Blood Purif. 2008;26:30-5. 